\title{
Dietary determinants of saturated fat intake in Irish children (5-12 years)
}

A. O'Connor ${ }^{1}$, M. Buffini ${ }^{1}$, A.P. Nugent ${ }^{1,2}$, J. Walton ${ }^{3}$, A. Flynn ${ }^{3}$ and B.A. McNulty ${ }^{1}$

${ }^{1} \mathrm{UCD}$ Institute of Food and Health, University College Dublin, Ireland; ${ }^{2}$ Institute for Global Food Security, Queens University Belfast, N. Ireland; ${ }^{3} \mathrm{School}$ of Food and Nutritional Sciences, University College Cork, Cork, Ireland.

\section{Introduction}

It is well established that elevated intakes of saturated fatty acids (SFA) are associated with an increased risk of chronic diseases such as diabetes mellitus, cardiovascular disease and some cancers ${ }^{(1)}$. In Ireland, current dietary guidelines recommend that dietary SFA should account for $\leq 10 \%$ of total energy (TE) in children over 5 years ${ }^{(2)}$; however, only $2 \%$ of Irish children are meeting this recommendation ${ }^{(3)}$. The aim of this analysis was to investigate the dietary sources and determinants of SFA intake in Irish children.
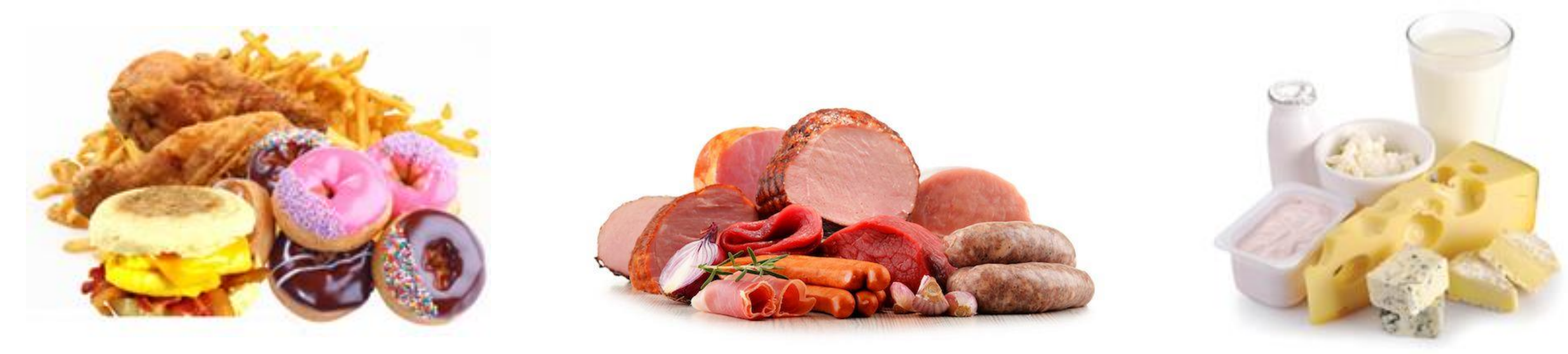

\section{M aterials \& M ethods}

Analyses were based on data from the National Children's Food Survey (NCFS; 2003-2004) which collected detailed food and beverage intake data from 7-d weighed food diaries from a nationally representative sample of 594 children aged 5-12 years (www.iuna.net). Dietary intakes were analysed using WISP@, which is based on McCance and Widdowson's The Composition of Foods, Sixth Edition ${ }^{(4)}$. Each food consumed was assigned to one of 27 food groups. The population was split into quartiles of \%TE from SFA (lowest, low, medium and high consumers) and dietary sources and determinants of SFA intake were calculated using SPSSC).
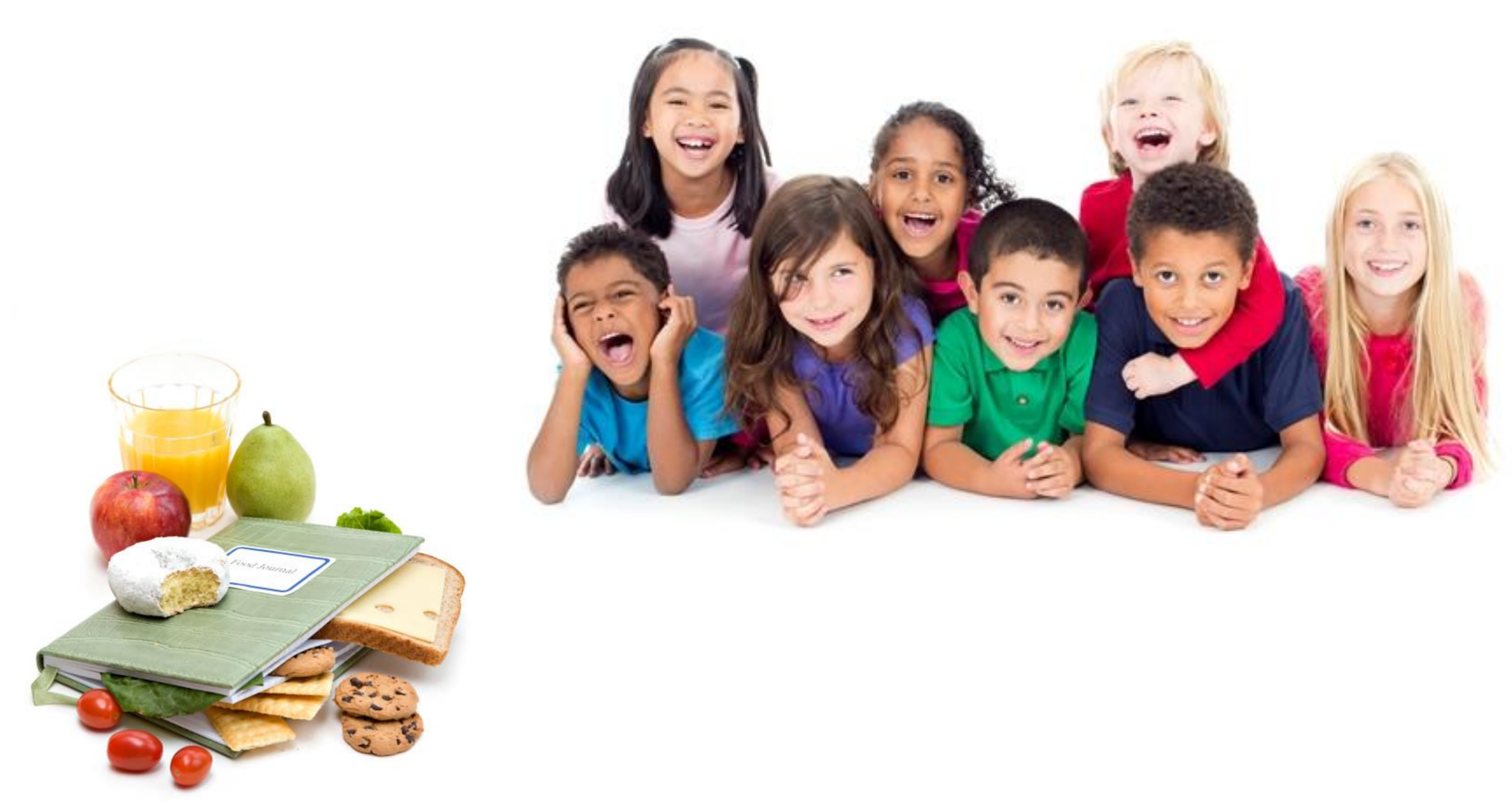

\section{Results \& Discussion}

There was no significant difference across quartiles in relation to gender, age and body mass index. Percentage TE from SFA increased significantly across all quartiles. In contrast, \%TE from carbohydrates and total sugars significantly decreased from the lowest to highest quartile $(p<0.001)$. 'Whole milk', 'sugar, confectionary and preserves', 'biscuits, cakes, pastries and buns' and 'meat products' were the four major contributors across all quartiles to SFA (\%TE). Comparisons between the lowest and highest consumers indicated that whole milk had the largest difference of $10.6 \%$ TE $\quad(p<0.001)$. In relation to micronutrients, a significant difference in calcium, vitamin $A$ and $E$ intakes were observed across the quartiles.

Table 1. Mean daily energy, macronutrient and fibre intakes across quartiles of mean daily saturated fat intake in Irish children (5-12years) for total population

\begin{tabular}{|c|c|c|c|c|c|c|c|c|c|}
\hline & \multirow{2}{*}{\multicolumn{2}{|c|}{$\begin{array}{l}\text { Lowest } \\
n=148\end{array}$}} & \multirow{2}{*}{\multicolumn{2}{|c|}{$\begin{array}{c}\text { Low } \\
n=148\end{array}$}} & \multirow{2}{*}{\multicolumn{2}{|c|}{$\begin{array}{c}\text { Medium } \\
n=148\end{array}$}} & \multirow{2}{*}{\multicolumn{3}{|c|}{$\begin{array}{c}\text { High } \\
n=148\end{array}$}} \\
\hline & & & & & & & & & \\
\hline & Mean & $\overline{S D}$ & Mean & $\overline{S D}$ & Mean & $\overline{S D}$ & Mean & SD & $P$ \\
\hline Saturated fat $(\mathrm{g} / \mathrm{d})$ & $21.2^{\mathrm{a}}$ & 5.2 & $25.9^{\mathrm{b}}$ & 5.7 & $28.1^{c}$ & 6.1 & $34.0^{d}$ & 7.9 & * \\
\hline Saturated fat (\%TE) & $11.7^{\mathrm{a}}$ & 1.1 & $13.7^{\mathrm{b}}$ & 0.5 & $15.3^{c}$ & 0.5 & $18.0^{\mathrm{d}}$ & 1.5 & $*$ \\
\hline Protein (\%TE) & 13.5 & 2.5 & 13.6 & 2.3 & 13.5 & 1.9 & 13.8 & 1.9 & ns \\
\hline Carbohydrate (\%TE) & $56.2^{\mathrm{a}}$ & 4.3 & $53.1^{b}$ & 3.6 & $51.0^{c}$ & 3.5 & $47.6^{d}$ & 3.3 & $*$ \\
\hline of which sugars (\%TE) & $25.2^{\mathrm{a}}$ & 6.3 & $23.9^{\mathrm{ab}}$ & 5.1 & $23.9^{\mathrm{ab}}$ & 4.9 & $22.7^{b}$ & 4.6 & $*$ \\
\hline Fat (\%TE) & $29.8^{\mathrm{a}}$ & 3.3 & $32.8^{b}$ & 2.7 & $35.0^{c}$ & 3.0 & $38.2^{d}$ & 2.7 & $*$ \\
\hline $\begin{array}{l}\text { Monounsaturated fat } \\
\text { (\%TE) }\end{array}$ & $10.5^{\mathrm{a}}$ & 1.6 & $11.3^{\mathrm{b}}$ & 1.5 & $12.0^{c}$ & 1.7 & $12.7^{d}$ & 1.5 & $*$ \\
\hline Polyunsaturated Fat (\%TE) & $5.2^{\mathrm{a}}$ & 1.4 & $5.0^{\mathrm{a}}$ & 1.3 & $4.9^{a b}$ & 1.4 & $4.6^{\mathrm{b}}$ & 1.0 & * \\
\hline
\end{tabular}

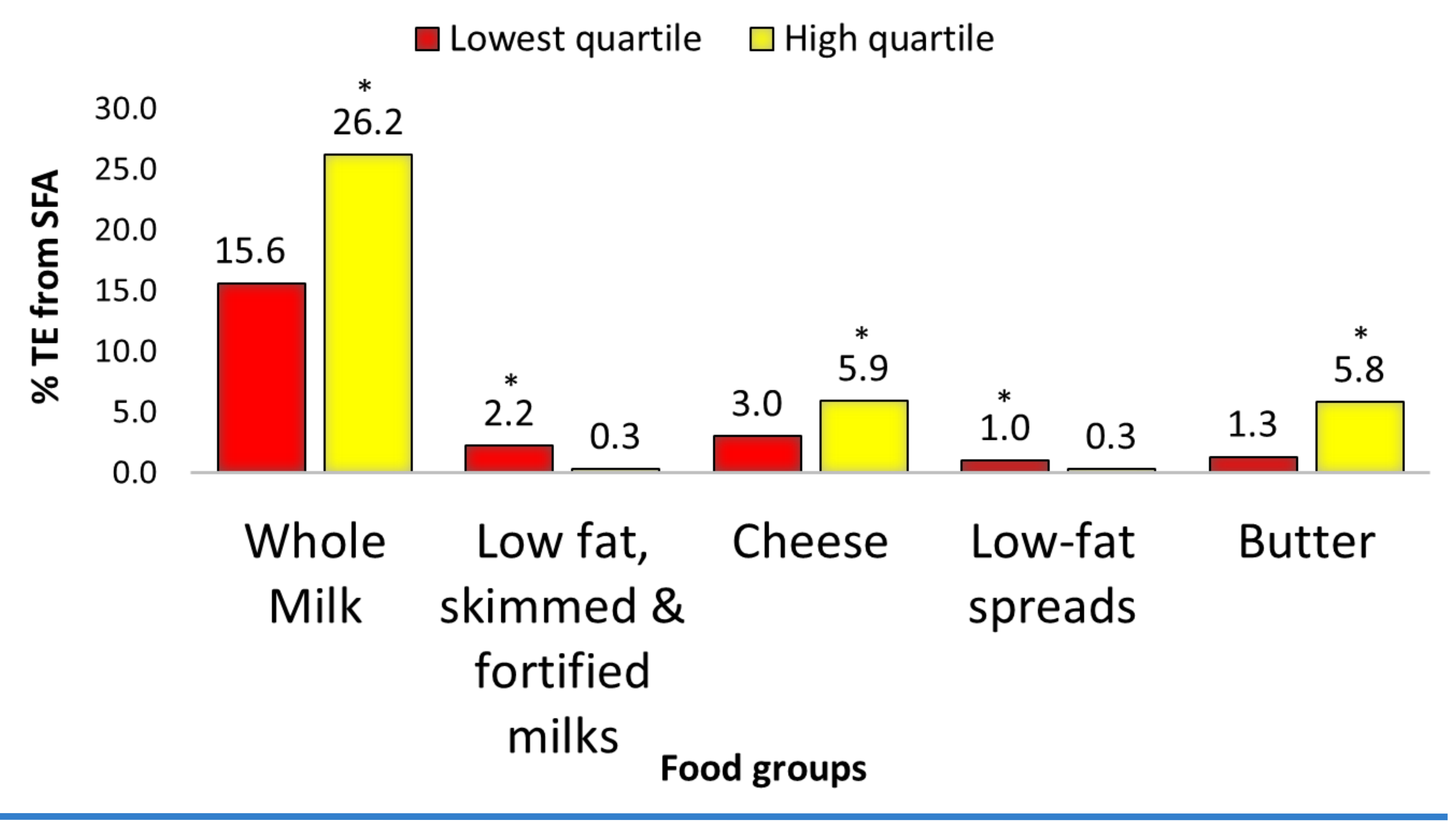

\section{Conclusion}

In conclusion, these findings indicate the dietary determinants of saturated fat intakes and may be useful for developing dietary strategies to improve compliance with national recommendations.

\section{References}

Egert S, Kratz M, Kannenbery F et al (2011) Eur J Nutr 50, 71- 79 Food Safety Authority of Ireland (2011) FSAI. Dublin, Ireland. Jbyce T, Wallace A, McCarthy S et al (2009) Pub H Nutr 12, 156-165 Food Standards Agency (2002) Royal Society of Chemistry. Cambridge.

\section{Acknowledgements:}

This research was funded by the Irish Department of Agriculture, Food and the Marine under the project 'National Children's Food Consumption Survey II' (15/F/673)

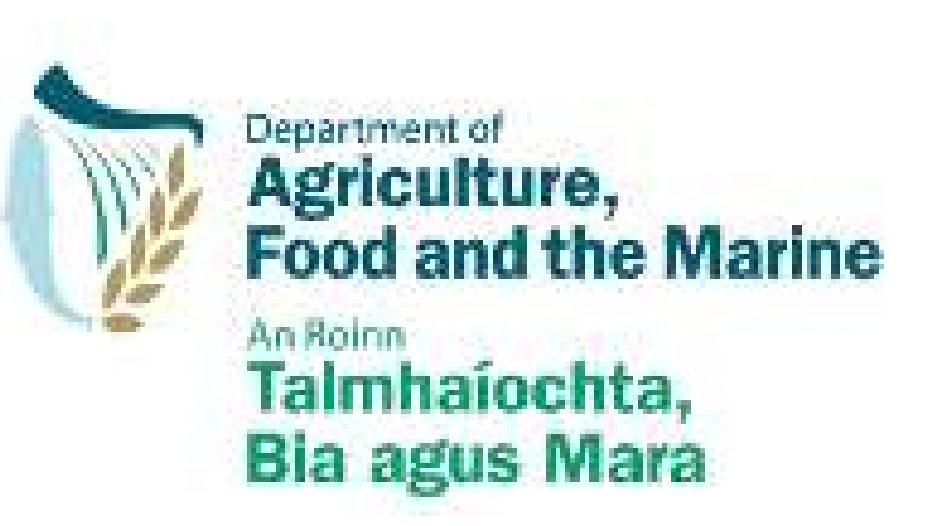
Talmhaiochta,
Bia agus Mara 